\title{
APUNTS SOBRE EXILI, LLENGUA I TRADUCCIÓ
}

\section{SOME REMARKS ON EXILE, LANGUAGE AND TRANSLATION}

\author{
Montserrat BaCARdí \\ Universitat Autònoma de Barcelona \\ montserrat.bacardí@uab.cat
}

Resum: A l'exili del 1939, la traducció hi va tenir un paper més aviat subsidiari. L'obra original hi era prioritària, perquè salvar els mots es va convertir en una urgència. Els traductors «professionals» van haver de servir-se d'altres llengües (del castellà, sobretot), mentre que els traductors «vocacionals» traduïen al català per a ells mateixos, per a l'esdevenidor. La premsa exiliada tan sols podia acollir algunes versions literàries testimonials o bé trasllats anònims de textos informatius. Les revistes Full Català, Quaderns de l'Exili i Lletres, publicades a Mèxic els anys quaranta, il-lustren concepcions confrontades de la llengua i la traducció.

Paraules clau: exili, traducció, llengua catalana, Full Català, Quaderns de l'Exili, Lletres, Lluís Ferran de Pol, Joan Sales, Agustí Bartra.

Abstract: In the 1939 exile, translation played a somewhat subsidiary role. Original works were the priority, because saving words had become urgent. "Professional" translators had to use other languages, especially Spanish, while "vocational" translators translated into Catalan for themselves, for the future. The press in exile could only access a few token literary translations or anonymous translations of informational documents. The journals Full Català, Quaderns de l'Exili and Lletres, published in Mexico in the I940s, illustrate differing conceptions of language and translation.

Key words: Exile, translation, Catalan language, Full Català, Quaderns de l'Exili, Lletres, Lluís Ferran de Pol, Joan Sales, Agustí Bartra. 


\section{MONTSERRAT BACARDÍ}

\section{APUNTS SOBRE EXILI, LLENGUA I TRADUCCIÓ*}

\section{ABANS D'ARA}

És una obvietat que la traducció havia jugat un paper capital en l'afaiçonament de la llengua durant les primeres dècades del segle xx. Les iniciatives col-lectives i individuals s'havien succeï i havien propiciat un esplet d'obres estrangeres reescrites en català inimaginable tan sols cinquanta anys enrere. Havia coincidit amb el procés de normativització emprès per Pompeu Fabra i sovint l'havia servit: l'un nodria l'altre, recíprocament, sobretot fins a la dècada dels vint, en què havien aparegut col-leccions tan inclinades a difondre traduccions com la «Biblioteca Popular» de L'Avenç, la «Biblioteca Popular dels Grans Mestres» o la «Biblioteca Literària». Després, tan sols havien pogut transcórrer uns pocs lustres de regularitat editorial, amb col-leccions senyeres com la de la «Fundació Bernat Metge», la «Biblioteca A Tot Vent» o els «Quaderns Literaris». La llista de traductors és igualment llarga i reputada, des de Joan Maragall, Maria Antònia Salvà o el mateix Fabra fins a Josep Carner, Carles Riba o Josep M. de Sagarra, passant per tota mena d'intel.lectuals que van deixar una petja inesborrable en tant que intermediaris de cultures foranes, com Joan Crexells, Andreu Nin o

$\left(^{*}\right)$ Aquest article s'inscriu en el Grup d'Estudi de la Traducció Catalana Contemporània (GETCC) (20I4, SGR 285), reconegut per l'Agència de gestió i ajuts universitaris de la Generalitat de Catalunya, i en el projecte «La traducción en el sistema literario catalán; exilio, género e ideología (I939-2000)», amb el número de referència FFI20IO-I985I-Co2-or, finançat pel Ministerio de Ciencia e Innovación. 
Bonaventura Ubach. La seva tasca com a forjadors de models lingüístics i literaris ha estat prou estudiada en alguns casos, com en els de Carner o Riba.

Aquest món es va esfondrar el 1939. No cal insistir que el franquisme va sepultar la llengua, en tots els àmbits públics, a les catacumbes. I la traducció, singularment $\mathrm{i}$ persistent, per tal com atorgava al català una condició d'universalitat i de modernitat que en qüestionava el caràcter folklòric a què s'havia pretès reduir. Vençut el nazisme a Europa i sota l'aquiescència de les potències aliades, era de més bon tolerar un aplec de poemes o una monografia local que no pas la versió d'un clàssic o d'un autor contemporani. Aquesta operació vivificava la llengua perseguida i li atorgava un nou prestigi. De fet, fins al 1962, amb canvis ineludibles en la política de publicacions del règim, les traduccions catalanes aparegudes al Principat, a les Illes Balears i al País Valencià són comptades $\mathrm{i}$, sobretot els deu primers anys, sempre excepcionals.

La derrota republicana va comportar un dels èxodes més massius i significats de l'Europa contemporània. Milers de persones van travessar la frontera les primeres setmanes del 1939, a la recerca de la llibertat perduda o simplement per salvar la vida. La supervivència i els ideals anaven de bracet (potser com poques vegades hi han anat després). Així que les circumstàncies ho van permetre, i davant els primers senyals d'una nova conflagració al cor d'Europa, els expatriats es van anar dispersant i molts van fer el salt al continent americà, on van trobar l'aixopluc de les colònies de l'emigració.

\section{EXILI I TRADUCCIÓ}

A recer dels antics casals i centres de trobada, els exiliats més compromesos van maldar per prosseguir la lluita més enllà de les fronteres. Entre els primers objectius, de seguida van plantejar-se la possibilitat d'editar en llengua catalana: revistes, opuscles, llibres... Calia fornir nous materials per a unes col-lectivitats que n'estaven faltades i deleroses; calia sadollar la nostàlgia i la melangia, l'enyorament paralitzador; calia recomençar de cap i de nou, amb una nova empenta malgrat l'ensopegada històrica. Les paraules inicials de la primera revista que va sortir a l'exili, La Revista dels Catalans d'Amèrica, l'octubre de 1939, ja invitaven a posar-s'hi: «Molts som fora del nostre estatge i ens el cal refer». En aquesta reconstrucció, un element agermanava: «Mentre conservem el dipòsit sagrat de la nostra llengua, res no és perdut» («Veus-aquí...» 1939: 5 i 6). 
Aquestes publicacions s'adreçaven a un públic potencial reduï, el qual, d'altra banda, de vegades tenia prou feines a cobrir les necessitats més elementals. Les revistes van fer crides reiterades a la conscienciació dels lectors envers els productes catalans. Si no s'assolien uns mínims de vendes, eren inviables, i es perdien preciosos elements polítics, socials i culturals cohesionadors. En qualsevol cas, els recursos i les disponibilitats d'emissors i de receptors eren limitats.

Les traduccions podien tenir-hi un lloc, en aquest mercat tan singular? Com ja va assenyalar Albert Manent en el seu estudi pioner, "Calia una cultura normal perquè les versions d'obres estrangeres fessin costat a les obres dels autors del país. I a l'exili hom donava prioritat a les obres originals» (1989: 220). Enmig d'un exili lingüístic ben tangible, sofert diàriament, o d'un «doble exili» (Duran 1998), la traducció comportava encara un nou estranyament: el viatge de la llengua estrangera a la pròpia en un context altrament estranger. Tanta alteritat resultava inassumible, quan, al capdavall, els lectors frisaven pel retrobament, per un retorn que s'endarreria més del compte.

Si de cas, el traductor exiliat podia ser més efectiu si practicava una espècie de traducció inversa, de la literatura catalana a les llengües dels països d'acollida (més factible, en general, quan era el castellà). Alguns hi van treballar, sempre ocasionalment i de vegades amb la complicitat d'editors catalans igualment expatriats, com Joan Grijalbo o Antoni López Llausàs. Hi havia una manera més operativa de donar a conèixer una cultura malmenada i, de retruc, de continuar el combat? En aquesta comesa, s'hi van esmerçar homes de lletres com Josep M. Francès o Joan Oliver. D'altres, com Agustí Bartra o Xavier Benguerel, amb propòsits semblants, van optar per autotraduir-se al castellà; o al francès, en els casos de Josep Carner o Ventura Gassol. Es tractava, fet i fet, de situar la tradició catalana en el mapa de les tradicions de les grans literatures veïnes.

Algunes de les traduccions al català aparegudes durant l'exili revelen un procés de negació de l'estrangeria, d'assimilació a la cultura d'arribada, d' «anostrament» radical, atès que no són presentades com a traduccions sinó com a obres «originals». Enlloc no s'indicava que provenien d'una altra llengua ni tampoc que, en el resultat final, hi hagués intervingut un reescriptor. Se n'encobria el caràcter d'obres foranes a fi que semblessin "catalanes», sobretot si no eren manifestament literàries. En la versió de L'esperit de Catalunya, de Josep Trueta, publicada a Mèxic el I950, s'havia ocultat la cooperació de Vicenç Riera Llorca, responsable del trasllat de l'original anglès (Riera Llorca 1994: I05). De la mateixa manera es procedia en llibres i opuscles de caire polític 
o, a la premsa, en les nombroses traduccions anònimes d'articles d'actualitat provinents, bàsicament, de l'anglès, el francès i l'italià. En tots aquests casos, la traducció era invisible $-\mathrm{o}$ es procurava que ho fos.

Tampoc les reedicions de traduccions podien saciar la set de productes autòctons del vast exili polític. Un cop més, l'alteritat s'hi feia massa present, en una situació vital de permanent estranyesa. Tan sols va ser reimprès, el 1946, un veritable clàssic, la Mireia de Maria Antònia Salvà, que ja havia passat a la història literària del país com una apropiació d'un poema fundacional d'un poeta germà, Frederic Mistral, per part d'una poeta inspirada. El procés d'aprehensió a les lletres autòctones ja havia fructificat anys enrere. Per això, ara podia arrenglerar-se en una Biblioteca Catalana, al costat d'Ausiàs Marc, Jacint Verdaguer o Agustí Bartra, i podia, fins i tot, ser objecte d'una doble edició: una de bibliòfil, amb un tiratge de dos-cents exemplars, i una altra de corrent, de mil exemplars (Férriz Roure 1997: I26).

La representació d'obres traduïdes no va gaudir de gaire més fortuna. Alguns casals de l'emigració, com el de Buenos Aires, podien presumir d'una dilatada tradició d'activitat teatral, centrada en la producció catalana, sense menystenir, però, alguns èxits europeus (Bacardí 2009: I8-2I). Si alguna vegada s'hi va recórrer, acabada la guerra, el fet no va passar desapercebut i va despertar més recels que entusiasmes. Per exemple, en ressenyar la posada en escena de Maria... no siguis tonta!, una adaptació de Rafael Riba i Llorenç Rodellas, del 1930, d’una comèdia de Ladislao Fodor, la revista Catalunya advertia de bon començament:

És clar que donat el nombre limitadíssim de representacions anuals que poden oferirnos els simpàtics actors del nostre quadre escènic no convé caure molt sovint en la temptació d'obres forasteres, doncs és ben evident que el que desitgem i necessitem els catalans de Buenos Aires és veure teatre català representat en català. Teatre català de totes les èpoques. Autors del segle passat i del present, bons i mediocres.

(«Teatre català» I943: 25)

En canvi, sí que les traduccions van tenir un cert reconeixement en els Jocs Florals de la Llengua Catalana a l'exili, itinerants, restablerts a Buenos Aires el 194I. A falta d'altres plataformes, molts escriptors que no hi haurien concursat a Barcelona s'hi van abocar, i de vegades per donar a conèixer obres traduïdes, regraciades entre un cúmul de premis i de distincions a obres originàriament catalanes. La "Motivació de la convocatòria» del primer any en subratllava l'ambició i la voluntat de suplència: «no es tracta, doncs, d'un certamen local o regional», sinó d'una crida «a tots els poetes, 
prosistes i conreadors de la nostra llengua escampats per tot el món» (Jocs Florals 1942: I2). Per això, un cop acabada la conflagració mundial, tant hi van participar residents de fora com de dins del país, i hi van ser reconeguts com a traductors Agustí Bartra, Josep Carner-Ribalta, Emili Granier Barrera, Carles Pi i Sunyer, Ramon Sastre o Joan Triadú (Faulí 2002). No tots els treballs que hi van presentar van sortir publicats, ni aleshores ni més endavant.

Unes quantes traduccions, poques, es van acollir a uns canals d'edició més convencionals, a l'empara de col-leccions de prestigi. En sobresurten les aparegudes a la «Biblioteca A Tot Vent», en la represa de Proa a Perpinyà: L'hereu de Ballantrae (I953), de R. L. Stevenson, L'estany del diable (1955), de George Sand, i Homes i ratolins (1964), de John Steinbeck. Les dues primeres, traduïdes per C. A. Jordana i Just Cabot, ja havien quedat enllestides abans de la victòria franquista, mentre que la tercera, obra de Manuel de Pedrolo, va aparèixer l'any de la concessió del premi Nobel a Steinbeck, just abans del retorn de Proa a Barcelona (Camps i Arbós 2004a: 62-64). Cap de les tres, clàssics dels segles XIX i XX, no oferia motius de possibles suspicàcies per a haver de veure la llum fora de les fronteres, fet que va ser criticat tant en papers públics com en papers privats. Des de les pàgines de Pont Blau, l'agost de 1955, Joan Fuster sentenciava que «totes aquelles obres que poden ésser publicades a l'interior [...] hi haurien d'ésser publicades» (I995: 189), mentre que Rafael Tasis i Ramon Xuriguera, en la correspondència, es mostraven més taxatius, i el 28 de febrer de 1954 Tasis escrivia: «Per anar a muntar una editorial a l'exili, no em sembla la cosa més indicada publicar llibres del segle passat, que tothom ha pogut llegir en castellà, i que haurien pogut passar perfectament sota la censura actual» (Camps i Arbós 20I0: 167). En definitiva, les tres obres potser no poden considerar-se pròpiament traduccions d'exili, encara que hi apareguessin.

\section{TRADUCCIÓ I EXILI}

La precarietat del mercat editorial — cultural— de l'exili, ja ho hem vist, no permetia albirar una mínima regularitat en la publicació de traduccions. Per als que hi persistien, els traductors més o menys vocacionals, sovint es convertia en una activitat privada, gairebé secreta o somorta, a mercè del pas del temps o d'algun atzar que la impulsés. Xavier Benguerel, Josep Carner-Ribalta, Emili Granier Barrera o 
Ramon Xuriguera van consumir moltes hores dels seus lleures reescrivint en català un grapat d'obres dels autors que admiraven perquè els plaïa, sense gaires perspectives de difusió.

Motivacions íntimes i, alhora, col-lectives els hi empenyien. Benguerel i CarnerRibalta es van inclinar per fer-se seva la poesia de Paul Valéry (entre altres simbolistes francesos). El primer va publicar-ne diferents versions, com quatre d'El cementiri marí (1947, 1956, I974 i 1984), i el segon va traslladar-ne les Poesies completes (I96I). En els seus llibres de memòries coincidien a remarcar que s'hi havien fixat, en una obra tan complexa i costosa de traduir, amb «esperit desafiador», com una «íntima venjança contra la ignorància franquista» (Carner-Ribalta 2009: 232-233), o bé amb «inqüestionables mires polítiques» (Benguerel 1974: 27). Hi havien persistit gràcies a l'esperit de «superació» (Carner-Ribalta 2009: 233) o, més eloqüentment, «per tal de sentir-me cada dia més aplomat en l'ús del meu idioma» (Benguerel 1982: 74), és a dir, per tal «d'entrar en possessió d'un idioma molt superior al que jo estava avesat a manipular» (Benguerel 1982: 153). La traducció esdevenia un aprenentatge personal i, a llarg termini, un triomf comú.

Aquesta doble força també havia esperonat Agustí Bartra a confegir una Antologia de la lírica nord-americana (1951). Com confessava en el prefaci, la idea inicial havia sorgit el mateix any 1939, al camp d'Adge, amb la lectura de The Albatros Book of Living Verse, de Louis Untermeyer (Bartra 1951: 7). Després, durant una colla d'anys de traduccions mercenàries al castellà, el projecte havia estat irrealitzable, fins que el 1949 va obtenir una beca de la Fundació Guggenheim per a dur-lo a terme. De fet, Bartra hauria pogut renunciar-hi perquè, en el moment de la concessió, simplement s'havia establert que havia de fer "treball creador en el camp de la poesia» (Murià 1990: 189). No tan sols hi va perseverar sinó que, un cop enllestida la tria i la traducció catalana, de seguida va emprendre la versió castellana, Antología de la poesía norteamericana (1952), amb notables variants en la selecció i el nombre de poemes respecte de la primera (Ruiz Casanova 20II: 236-237). Tanmateix, en les cartes intercanviades amb Joan Fuster, Bartra es mostrava distant respecte de qualsevol identificació personal amb els poetes traduïts: fora de tres o quatre, «la resta em diu ben poca cosa». Atorgava a l'obra, això sí, un valor de revulsiu en el panorama literari català: «crec que a Catalunya aquest llibre pot ser útil per la força esbatanadora que pugui significar» (Fuster 1998: I48). La voluntat de servei al poble vençut, doncs, s'havia imposat i havia redundat en els interessos personals. Més de mig segle després, encara és vista com «una de les 
propostes de traducció més originals, més ambicioses i més sofisticades de la literatura catalana del segle XX» (Abrams 2009: 70), «motiu d'orgull a qualsevol literatura europea de l'època» (Desclot 2007: 30).

La fi de la guerra civil va conduir Ramon Xuriguera a França. Sortejant adversitats de diversos ordres, va desplegar l'activisme polític i cultural, l'escriptura i la traducció. El 1942 va traslladar El gran Meaulnes, l'única novel-la d'Alain-Fournier. Les sortides editorials havien quedat estroncades, i la traducció encara avui roman inèdita. Una circumstància que no devia pesar-li gaire, atès que l'any següent, el 1943, va iniciar la versió d'un clàssic incontestable, Madame Bovary, de Gustave Flaubert, que no havia estat mai traduït al català. En la pau forçosa del confinament a Mouleydier, aquestes reescriptures probablement exercien un efecte balsàmic en el seu esperit. El seu germà, Joan Baptista Xuriguera, li feia notar el «privilegi» de la situació, en una carta del 27 de gener de 1944: «Tant per la traducció, com per a fer el teu assaig, es necessita temps i calma, que potser t'hauria estat difícil de trobar a casa nostra» (Camps i Arbós 2004: 493). L'assaig a què feia referència va esdevenir el pròleg de la traducció, que no va sortir publicada fins al cap de vint anys (1965), poc abans de la mort de Xuriguera. A l'exili, la majoria de traduccions eren per al futur.

\section{CONTINUÏTAT I RUPTURA}

En l'article «L'exili literari català: continuïtat i ruptura», l'any 2000 Jordi Castellanos sostenia que tota la literatura expatriada gravita al voltant d'una disjuntiva, no sempre excloent: la desfeta de la guerra va provocar un sentiment de fatalitat, d'infortuni irreparable, i, alhora, la convicció que es presentava "una oportunitat per replantejar de cap i de nou les bases de la vida cultural i literària de Catalunya» (2000: 3I). Aquest revisionisme es va evidenciar en totes les publicacions periòdiques més o menys insistentment, tant és que fossin d'un tarannà com d'un altre. El passat recent, d'una manera o altra, es manifestava en articles, assaigs, narracions o poemes. I mentre alguns intel.lectuals s'inclinaven per afavorir la represa de la cultura obstruïda, altres apostaven, a partir de l'examen de les defallences passades, per fer foc nou i aprofitar l'avinentesa per a construir uns fonaments competencials més sòlids. Castellanos situava en la primera línea el nucli de refugiats a Santiago de Xile (Xavier Benguerel, Josep Ferrater Mora, Domènec Guansé, Joan Oliver i Francesc Trabal) i, en la segona, 
el grup dels Quaderns de l'Exili (Josep M. Ametlla, Lluís Ferran de Pol, Raimon Galí i Joan Sales en van ser els quatre redactors inicials).

A Mèxic mateix havien conviscut les dues tendències, l'una més intel.lectualista que l'altra, com s'observa en tres de les revistes que hi van aparèixer la dècada dels quaranta, Full Català (194I-I942), Quaderns de l'Exili (1943-I947) i Lletres (1944-I948), $i$ en les activitats que els seus impulsors van desenvolupar aquells anys. No solament propugnaven diferents concepcions de literatura, sinó també diferents models de llengua i, de retop, de traducció.

El Full Català, potser com cap altra publicació, és un símbol de la continuïtat i la ruptura, a causa de l'evolució que va seguir. En el primer número s'especificava que sortia «sota la cura» de Josep Carner, Lluís Ferran de Pol, Pere Matalonga i Josep M. Miquel i Vergés. Com que «acollia de fet tots els escriptors exiliats", va convertirse en "una mena de calaix de sastre» (Ferran de Pol 1984: 23) o en un «magazine de cultura amb finalitat bàsicament testimonial» (Casacuberta I889: 90). Poc després l'ideari estètic de Carner i de Ferran de Pol se separaven i, cadascun amb els seus acòlits, encarnaven dues actituds antagòniques. Joan Sales va exercir d'abanderat de la facció «vitalista» i, a partir del número 6, que va començar a col-laborar a la revista, hi va imprimir un nou caràcter i va minimitzar la facció «culturalista». El número 8-9, extraordinari, dedicat als Jocs Florals amb motiu de la celebració de l'efemèride a Mèxic, marca el punt àlgid de la feble convivència entre tots dos capteniments. $\mathrm{Al}$ mateix temps que s'hi reproduïa el discurs del president, Josep Carner, i una mostra d'alguns dels textos premiats, Ferran de Pol i Sales no s'estaven de desaprovar-los conceptualment, per bé que n'apreciaven l'efecte propagandístic. En qualsevol cas, jutjaven aquell monogràfic com «una mena de parèntesi en les nostres tasques habituals» (Sales I942a: 3). De seguida les van reprendre i van convertir el Full Català en un assaig dels Quaderns de l'Exili.

Algunes seccions de la primera època no van perdurar, com «Els escriptors catalans i llur aportació obligada a la bibliografia castellana», que anava encapçalada amb una nota crítica i reivindicativa: «La llista ens parla eloqüentment de l'oblit imperdonable que els organismes d'ajut han comès vers la llengua catalana» («Els escriptors» 194I: 2); també va quedar limitada a un número (el segon) la secció «Col-laboradors hispanoamericans», que pretenia oferir traduccions catalanes d'escriptors coetanis dels països d'acollença, fruit de la pruija de Carner de «posar en contacte els intel-lectuals catalans de l'emigració amb els intel-lectuals mexicans» (Calders I991: 47), i que es va reduir 
a un retrat de Benjamín Jarnés de «Barcelona de nit». En canvi, es van consolidar els articles sobre aspectes relacionats amb la literatura i la traducció: l'anomenada Bíblia valenciana, Stendhal, Arthur Rimbaud (amb el trasllat d'Agustí Bartra d'un fragment d'Una temporada a l'infern), Frederic Mistral, el comte Arnau, les traduccions dels clàssics grecollatins, la versió castellana de Josep Conangla i Fontanilles d'una antologia de poesia catalana... Van sovintejar també les traduccions anònimes d'articles de premsa i, a partir del número io, de «la legislació que els castellans han donat a Catalunya aquests últims temps», a fi i efecte que «ens ajudi a pensar més sovint en la sort tràgica dels nostres Països» ("Catalunya envaïda» I942: IO).

Lúnic apartat que es va mantenir pràcticament en tots els números va ser «Perquè el vostre infant llegeixi en català», el qual es feia eco d'una de les preocupacions quotidianes més vives de l'expatriació: «Després de més de dos anys d'exili no s'ha endegat res a favor de l'infant català. La llengua materna li fuig dels llavis, barrejada amb modismes forasters» («La caputxeta» 194I: I8). Des del 1939, en el primer número de La Revista dels Catalans d'Amèrica, ja havia estat reclamada l'ensenyança del català en les institucions docents creades a Mèxic pels representants del govern de la República (Just 1939: 43-44), fet que no es va produir mai. Al Full Català les narracions catalanes — de Verdaguer, Alcover, Carner o Calders - s'alternaven amb les d'altres procedències — de Les mil i una nits, Perrault, els germans Grimm, Andersen o Mistral—, les quals en bona part ja havien estat traduïdes abans de la derrota — per Alfons Maseras, Carles Riba o Marià Manent—, o bé no anaven signades o bé eren acabades d'interpretar — com, en el número II, «Un conte maia explicat per Ferran de Pol». De vegades s'acomboiaven amb breus notes introductòries i interpretatives. En destaca la que acompanyava «La bella dorment al bosc», inclosa en el número monogràfic dels Jocs Florals, que proposava una lectura del relat tan polititzada com sorprenent («La bella» 1942: 27):

Ara que heu llegit aquesta rondalla de Perrault, traduïda al català per Marià Manent, penseu una estona en el significat que pot tenir aquesta història tan bonica.

Qui us penseu que era la princesa? No era altra que la Llengua Catalana.

I el príncep que desencantà la princesa? No va ser altre que el poeta Bonaventura Carles Aribau, que l'any 1833 amb la seva Oda a la Pàtria ressuscitava la nostra llengua nacional.

Les sis fades que li van fer dons, eren Grècia, Roma, Provença, totes les terres d'on ens van venir les coses bones i boniques.

Però la fada vella i envejosa de qui ningú no se’n recordava, era Castella.

Quan la princesa va tenir Is anys, o sigui quan la Llengua Catalana començava a ser gran i a fer d'allò més goig, va quedar adormida, i adormida es va estar molt de temps — cent anys 
com diu el conte. Amb ella, van quedar encantats tots aquells cavallers del seu castell, que no eren altres que els nostres herois d'altres temps, els mateixos que havien fet poderosa la nostra Pàtria plantant les quatre barres per tot arreu.

A mesura que el Full Català quedava en mans de Ferran de Pol i Sales, amb Miquel i Vergés com a director nominal des del número io, la cultura - la llengua, la literatura, la traducció... - era concebuda com un mer instrument al servei d'una ideologia «regeneradora», destinada a redreçar definitivament el país.

De la mateixa manera que s'oferien lectures per a la mainada, amb un propòsit didàctic semblant, en el número 6 del Full Català Joan Sales iniciava la secció «Qüestions de llenguatge», que combinava l'exposició d'aspectes gramaticals concrets amb d'altres d'estilística. En essència, Sales ja hi defensava el model de llengua que després, un cop retornat a Barcelona, va aplicar a "El Club dels Novel-listes» i va argüir en nombrosos textos. D'acord amb la idea de la necessitat d'una literatura «funcional», arrelada a la societat, advocava per una llengua pràctica, àgil i moderna. Així, combatia els arcaismes, els neologismes, els suposats preciosismes, els recargolaments i els barroquismes, la falta d'espontaneïtat, l'estranyesa... Hereu manifest de Pompeu Fabra i futur col-laborador de Joan Coromines, no es va cansar mai de repetir que "la correcció i la naturalitat, lluny d'estar renyides, van sempre juntes», de manera que, a tall de "fórmula»: "cal "parlar bé"; i —un cop aconseguit— escriure "tal com es parla" " (Sales 1942b: IO). Ferran de Pol compartia aquest programa i tot sovint se l'aplicava i hi afegia nous matisos: «Senzillesa, vida, força, són ara preocupacions que han vingut a substituir el culte del Diccionari i de la Gramàtica» (Ferran de Pol 1942: 3).

\section{TRADUIR EN SILENCI}

El programa revisionista que van orquestrar Lluís Ferran de Pol i Joan Sales al Full Català, en què la llengua i la literatura hi tenien un cert protagonisme indirecte, van desenvolupar-lo a bastament als Quaderns de l'Exili. Amb bones dosis de «messianisme» $\mathrm{i}$ alhora d' «esperit de sacrifici», es tractava de plantejar «les bases d'una segona Renaixença que havia d'assegurar la supervivència de la Nació» (Puimedon 1996: II3). Quedava ben explícit en el cinquè punt dels "principis» inicials amb què van presentar-se, tal vegada el que va fer més forrolla («Propòsit» 1943: 2): 


\begin{abstract}
Defensem la cultura basada en els caràcters nacionals i posada al servei de l'home. Rebutgem l'intel.lectualisme, la deshumanització i la supèrbia de tota manifestació que s'anomeni cultural a si mateixa, però que pretengui sobrepassar o menystenir l'Home. Rebutgem una cultura sense contingut i que es nodria indefinidament dels seus propis residus. Entenem que l'home val més que el seu rastre, el contingut més que el continent, el pensament més que la forma. Ambicionem un estil directe, senzill i digne, subordinat a l'obra.
\end{abstract}

Tot seguit, a la pàgina següent, Ferran de Pol signava un article «Contra l'obra d'en Josep Carner: Misterio de Quanaxhuata» que esdevenia un avís del to combatiu de la publicació - i, a la llarga, «un dels treballs més citats de la revista i de l'exili en general» (Garcia i Raffi 1998: 230). Li retreia que hagués escrit una obra de creació en castellà, pel grau de confusió que això comportava entre el públic mexicà: «Carner [...] no té dret a fer passar el nostre país com a bilingüe als ulls dels hispanoamericans», més que més tenint en compte que, al seu parer, «una de les tares més penoses és el fenomen del bilingüisme» (Ferran de Pol 1943: 3).

L'editorial del segon número, una nova declaració d'intencions, servia per a fixar la visió del grup de la història literària del darrer segle, posteriorment ampliada i glossada en nombrosos articles. En essència, consideraven que, després de dècades de renaixença ininterrompuda, sempre en línia ascendent, les lletres catalanes van sofrir un llarg interludi a causa del Noucentisme, que va negar les essències nacionals i va decantar-se per la importació sistemàtica de models forans («Retorn» 1943: I-2):

De sobte, la línia es torç. Eugeni d'Ors ha aparegut; i ell i la turba dels seus epígons tenen la virtut de glaçar la Renaixença catalana. S'obliden de València [...] perquè volen ser «europeus». I una literatura que ja tenia una fesomia pròpia [...] adopta la fesomia del simi. De república literària independent que érem des del I84I [...] caiem al rang de colònia imitativa, i perdem més de la meitat del territori...

«Els òrsides», el conegut article de Joan Sales, constitueix el text programàtic de la «manifestació extrema d'antinoucentisme» (Murgades 1996: I26) que exhibien els redactors dels Quaderns de l'Exili. Parteix de la premissa que l'obra d'Eugeni d'Ors recorda en molts aspectes la de Francesc Vicent Garcia, el Rector de Vallfogona; entre altres, en el fet que "tots dos van voler "universalitzar" la literatura catalana a base d'introduir-hi tota mena d'influències estrangeres a la moda del seu moment...» (Sales 1945: 9). El primer hi va insuflar les novetats castellanes i, el segon, les franceses; en tots dos casos, d'una manera acrítica i abusiva, segons Sales, fins al punt de desnaturalitzar la literatura i la llengua pròpies, atès que s'havien vist envaïdes per una allau 
de traduccions. I la traducció, als seus ulls, s'havia de practicar amb mesura i sense escarafalls, «en silenci» (Sales I945: I0):

I ¿̧sabeu què era aquest famós «imperialisme» òrsida? Era... traduir! [...]

Traduir és cosa necessària i normal; i tant ho és, que no té a penes importància, ni —fora de casos singularíssims - cal esmentar-ho en la història literària d'un país. Quan un país és sa, la tasca de traduir es fa modestament, en silenci. I es fa de tal manera que vénen a ser traduïdes obres de literatures estrangeres molt diverses, les quals, neutralitzant-se les unes a les altres, no pertorben els caràcters nacionals del país on són traduïdes.

Però si una literatura estrangera és introduïda en massa en un país, sense guardar proporció amb les altres, i sobretot si no hi ha cap motiu per justificar la desproporció, cal sospitar que es tracta d'un cas de provincianisme del país traductor respecte del traduït. Gràcies als òrsides, això es va produir a Catalunya respecte de França. La literatura francesa ens va venir com una allau que ho va submergir tot.

El mitjà expressiu dels «òrsides» era igualment objecte de blasme per part de Sales: «una "prosa” que, a força de circumloquis "estilístics" i de "lirisme", ja començava a assemblar-se a les cartes que les criades escriuen als quintos» (Sales i945: IO). També per contraposició, doncs, postulava un ús natural de la llengua, proper a l'oralitat.

La condemna a les influències estrangeres poc assimilades — recollida per alguna altra veu de l'exili, com la de Manuel Andújar, que titllava els escriptors catalans de "postizos afrancesados" (I949: 18) - es va convertir en un motiu recurrent dels Quaderns de l'Exili, en consonància amb la distinció que planava arreu entre "Cultura i "cultura" ", servida sovint en un to burleta i estripat: «Si un pixatinters que s'ha fet una "cultura" a esgarrapades en una cofurna de Sants imita Paul Valéry, per exemple, ens farà gràcia o llàstima, però és impossible que ningú [...] se'l prengui seriosament" (Ferran de Pol I944: IO). En canvi, a propòsit de la reedició de Mireia, el mateix Ferran de Pol suggeria una captació a tots els efectes de l'obra de Frederic Mistral a les lletres catalanes, un cop fracassat l'intent de revitalització de la literatura provençal: "potser, el destí final de Mireia i, en general, de tota l'obra de Mistral, serà de sofrir una mena d'incorporació amorosa a la literatura catalana» (Ferran de Pol 1946: 5). D'altra banda, com a conseqüència de l'anhel de "catalanitzar» la tradició del País Valencià, en el penúltim número, consagrat a "L'etnos ibèrica», s'oferia un fragment de la novel.la Sónnica, la cortesana, de Blasco Ibáñez, com si hagués estat escrita en català, sense deixar cap pista que era una traducció.

En tant que fruits "culturals», és a dir, desarrelats i estèrils, eren censurades, en general, les publicacions de l'exili, tant les revistes com els llibres — i, no cal dir-ho, 
els Jocs Florals: servien per a tranquil-litzar consciències, però no aconseguien implantar-se entre una població cada vegada més acomodada ni tampoc incidir-hi gaire. Els Quaderns de l'Exili, que es finançaven amb la publicitat i es repartien de franc, van assolir tiratges molt elevats, fins als quatre mil exemplars del darrer número. Amb tot, els redactors es mantenien insatisfets, perquè «l'exili és força semblant a la presó», amb escassa capacitat de maniobrar i de construir. En realitat, "vam fer un periòdic perquè no podíem fer res més», però «sense un ideal i sense un designi de lluita, l'exili ¿és gran cosa més que una conveniència o un temor?» («I94I-1946» 1946: I i 3).

El 1933 Joan Sales havia quedat primer (amb Manuel González Alba) en unes oposicions de català presidides per Pompeu Fabra. Mentre estudiava dret va treballar com a professor a l'Extensió d'Ensenyament Tècnic de la Generalitat. A l'exili va aprendre l'ofici de linotipista i ell va ser el responsable de confeccionar, materialment, els Quaderns de l'Exili. Al costat de rebentades i penjaments, van rebre cartes de felicitació de diverses personalitats i les van incloure en els darrers números; entre altres, dues de ben destacades en el terreny lingüístic: Joan Coromines, que en valorava la «digna presentació material i el llenguatge correcte, tan poc difós en el nostre temps» (Coromines 1946: 4), i Pompeu Fabra, que en feia una lloança semblant: «El català dels Quaderns de l'Exili [...] és quelcom més que un català gramaticalment correcte, cosa que m'és plaent de constatar en un temps en què ni a escriure un català passador arriben molts que no es cansen de fer paraula del seu amor a la nostra llengua» (Fabra 1947: 9).

\section{L'ART DE TRADUIR}

En el penúltim número del Full Català, Sales ja havia fiscalitzat el llenguatge de L'estel sobre el mur (1942), d'Agustí Bartra. El situava sota l'estela d'Eugeni d'Ors i de Josep Carner, simple "epígon del simbolisme francès [...] i altres escoles estrangeres», i el qualificava, en síntesi, d' "academicista» i de "conservador", alhora que li retreia construccions «revesses al geni del nostre idioma» (Sales 1942c: 7). Per argumentar-ho adduïa alguns trets morfològics, sintàctics, lèxics i estilístics emprats recurrentment per Bartra. Uns quants mesos després, des de les pàgines dels Quaderns de l'Exili, Josep M. Miquel i Vergés signava una ressenya de Xabola, novel.la de Bartra prologada per Carner, que semblava dictada per Sales (de fet, en citava la crítica del Full Català), per 
tal com, sense entrar tant en detall, li reprotxava també l'ús sovintejat de «barbarismes» que provenien, sobretot, de "construccions acastellanades" (Miquel i Vergés 1943: 4).

La polèmica estava servida. En la colònia catalana establerta a Mèxic havien sorgit dos bàndols irreconciliables. Més enllà de les possibles desavinences personals, hi pesaven força les d'ordre literari i lingüístic. Tan sols vuit mesos després de l'aparició dels Quaderns de l'Exili naixia Lletres, que duia el subtítol de Revista Literària Catalana, per fer ben explícit el seu caràcter apolític i per separar-se dels Quaderns. Una espectadora implicada en els fets, l'escriptora Anna Murià, muller d'Agustí Bartra, molts anys després explicava com s'havia concebut Lletres, encara amb tota l'escalfor del moment (Murià 1990: I65):

Una de llurs múltiples mossegades [de Quaderns de l'Exili] consistí a publicar una crítica adversa de Xabola abans que el llibre sortís, aprofitant el privilegi d'un dels tres de conèixer-ne el text gràcies al seu treball en una linotip; per cert que el text es basava en qüestions gramaticals i que aquell que donava la cara signant acostumava a escriure amb faltes d'ortografia. [...]

L'activitat d'aquesta secta desequilibrada féu necessària la creació d'una revista seriosa per un grup intel-ligent. Calders i Bartra en parlaren i decidiren realitzar la idea; amb Jordi Vallès i Roura-Parella, formaren un petit grup a l'entorn de Carner. Aconseguiren que CostaAmic acceptés d'ésser l'editor i iniciaren la revista Lletres, el primer número de la qual sortí el maig del 1944 .

De seguida Bartra es va convertir en l'artífex de la revista, i la seva petja hi és present tothora (si bé no va figurar-hi com a director fins a l'últim número). De ritme irregular, en van aparèixer deu números, el darrer pel gener de 1948. A diferència dels Quaderns, el tiratge devia ser baix, perquè «la singularitat d'ésser l'única revista de l'exili que responia al seu títol no li aportà anuncis ni gaire mecenatge» (Manent I989: 76) i, en paraules d'Anna Murià, «si n'aconseguíem col-locar uns cent exemplars ja fèiem prou» (Grifell I992: 6I).

La «Presentació» del primer número també constituïa una declaració de principis, amb al-lusions velades constants als Quaderns de l'Exili. Entesa com un «acte de fe i de militància», palesava que obeïa únicament al desig de «donar la continuïtat possible al moviment literari de Catalunya», fora de qualsevol filiació ideològica, dels límits «d'un grup d'escriptors expressament reduït, de dogmatisme ultrancer o de cleda exclusiva» —els Quaderns, en un editorial, s'havien definit com un «revista de grup" (Ferran de Pol 1945: I).

D'altra banda, combatien la idea de la inutilitat de l'exili si no era per a continuar lluitant, tan vehementment defensada pels homes dels Quaderns, i sostenien que 
«l'exili no és blanor», que l'esperit creatiu necessita temps per a poder fructificar i que, al capdavall, el compromís artístic també és un compromís ("Presentació» 1944: I).

Com remarcava el subtítol, Lletres era una revista manifestament «literària», talment hagués estat publicada en unes condicions «normals» d'un país «normal». Il.lustrada per Pere Calders, es nodria de poemes, narracions i assaigs breus, tant originals com traduïts. El tribut i homenatge a Carner — «la mistificació de Carner» (Casals 1992: 199) — es manifestava en col-laboracions seves en els sis primers números, fins que va partir de Mèxic, i encara en el vuitè; en el setè, l'article d'obertura era dedicat al "Comiat a Josep Carner», i Agustí Bartra hi constatava que "la vostra presència entre nosaltres ha estat un exemple» (Bartra 1945: I). Així mateix, hi sovintejaven les firmes del nucli fundador de la revista i més proper a Bartra - Calders, Murià, Josep Roure-Parella i Jordi Vallès - i, de tant en tant, les de la seva xarxa de relacions: Avel-lí Artís-Gener, Josep Carner-Ribalta, Josep M. Murià, Vicenç Riera Llorca o Mercè Rodoreda.

Tal vegada per convicció o tal vegada perquè el nombre de col-laboradors era reduït, la revista va recórrer gairebé en cada número a les traduccions, fet que l'emparenta a l'esperit inicial del Full Català i l'allunya dels Quaderns de l'Exili. Pels seus coneixements de llengües i pels seus interessos personals, Bartra va ser el traductor més prolífic, amb traduccions signades (segurament, també cal atribuir-li les anònimes) en cinc dels deu números publicats. Va arranjar-ne de Louis Aragon, John Keats, Paul Valéry, Walt Whitman i una primera mostra "De la lírica nord-americana»: composicions de Robert Frost, Wallace Stevens i Wilbert Snow, quan encara faltaven tres anys perquè sortís a llum Una antologia de la lírica nord-americana. Els altres traductors només van signar, generalment, amb les inicials: Francesc de Sales Aguiló, Antoni Ribera, Riera Llorca i Roure-Parella. Les seves contribucions són força heterogènies: cançons o adaptacions de Shakespeare, poemes de Hölderlin o José Asunción Silva i narracions d'Andrejev, Saki, Saroyan o Anna Seghers —a qui Anna Murià havia conegut casualment en un parc de Mèxic, on també vivia exiliada (Bacardí 2004: 96). A més, cada número solia albergar, en lletres més grosses, paraules emblemàtiques de pensadors o creadors destacats, que actuaven a tall de proclama i divisa, i sense fer constar si eren traduïdes o no: en van ser seleccionades de Sòcrates, Sal.lusti, Lucreci, Jordi de Sant Jordi, Keats, Blake, Rilke, Thoreau, Prat de la Riba i Picasso.

Per a la història i la teoria de la traducció catalanes constitueix una fita la publicació dels aforismes «De l'art de traduir», de Josep Carner, en el tercer número, 
corresponent al juliol de 1944. Amb una llarga experiència en aquest camp, Carner hi va formular idees, en un to doctrinari i sentenciós (com és propi del gènere), que després han estat tan profusament citades que han passat a formar part del patrimoni col-lectiu. Hiva combinar les reflexions especulatives i els consells pràctics amb l'enginy i l'humor. Pel que fa a la llengua d'arribada, va proporcionar una recomanació que ha esdevingut cèlebre, i que en bona mesura responia a la seva manera de procedir (Carner 1944: 4):

De l'esclavatge i angúnies de l'equivalència, no se n'ha de poder veure cap rastre penós. No es tradueix per paraules destriades, sinó per frases senceres, això és, per cops d'ala intellectuals; i tota frase que no aconsegueixi pas artísticament un aire d'espontaneïtat, no és bona sinó per llençar.

En síntesi, mentre que per als cappares dels Quaderns de l'Exili la traducció, com a manifestació «cultural», podia resultar altament perillosa per a la literatura i la llengua d'arribada si no es practicava en la mida justa i, sobretot, proporcionada a la producció autòctona (com ho havia estat, de contraproduent, durant el Noucentisme), els impulsors de Lletres li atorgaven un prestigi inusual en les publicacions de l'exili —i de l'interior-, la situaven com una categoria literària al costat dels escrits originals i li conferien un desenvolupament teòric. Si els uns advocaven per «traduir en silenci», els altres maldaven per forjar un «art de traduir».

\section{SUPERVIVENT D'UN CANT REMOT}

Josep Carner començava el poema «Si em vaga...», d'Absència (1957), amb aquests versos: «Viuré, si em vaga encar de viure, / supervivent d'un cant remot» (Carner 1992: I2I2). Com ha estat prou observat, l'exiliat, per naturalesa, és un supervivent, un nàufrag escàpol que mira de cercar nous camins o que per ventura s'estanca en els que ja són perduts. Sigui com vulgui, no pot defugir la condició de separació i desarrelament, d'«extraterritorial» (Steiner 2002), més pronunciada en funció del temps que passa a fora, de l'acompanyament que duu, de les noves possibilitats que se li presenten... Així, inexorablement, «el desterrament condueix al destemps» (Espinós 2000: 257) o, en altres mots, «una vida de exilio transcurre de acuerdo con un calendario diferente» (Said 2005: 195). L'exiliat no és tan sols transfronterer, sinó que també tendeix 
a convertir-se en «atemporal», situat fora del present d' "abans», que ja no respira ni controla, i del present d' "ara», que li passa per la vora o se li esmuny entre les mans sense adonar-se'n. Tot se'n ressent. També, la llengua, que mai no s'atura. Per contra, la pròpia dels exiliats, fora del terrer, es manté inamovible, en estat passiu: «la llengua subsisteix només en el ghetto i no es pot ni renovar ni seguir el desenvolupament normal del país d'origen» (Soler 1997: I00), interferida, si de cas, per la llengua del país d'adopció. El «cant» es torna «remot».

L'exili, com dèiem, ho és del país i de la llengua. Els traductors van haver d'enfrontar-se a aquest doble exili, a més de la inexistència d'un mercat regular i de la falta d'un públic àvid de llibres traduïts. Si per a escriure obres pròpies, la llengua potser ja pecava d'encarcarament, per a reescriure'n d'alienes, encara més: posar-se en la pell de l'altre exigeix un grau de flexibilitat —i d'actualització- de l'idioma més gran, perquè el marge de maniobra és més estret. Qui havia estat director de l'Oficina de Correcció d'Estil de la Generalitat, autor de diversos manuals de divulgació gramatical i traductor de Shakespeare, Stevenson o Virginia Woolf, Cèsar-August Jordana, el 8 d'abril de I94I escrivia a Agustí Bartra: «de tant llegir i escriure en castellà, estic perdent el meu propi idioma»; idea que reblava uns quants anys després, el i8 de juny de 1944: «he d'escriure en castellà (o sud-americà, que no és ben bé igual) i com que jo no sóc tan llenguado com vosaltres, el meu català s'ha espatllat tant que no m'atreveixo a escriure res en la meva llengua natural» (Correspondència 2005: II i i6). Així i tot, hi va escriure El Rusio i el Pelao (1950) i El món de Joan Ferrer (I97I) i hi va traduir Els bandolers, de Schiller, i Egmont, de Goethe, de l'alemany, llengua que havia estudiat pel seu compte a Buenos Aires, mentre es guanyava les garrofes traduint a preu fet de l'anglès al castellà. Ningú no les hi havia demanades, aquestes versions, i encara són inèdites. Si s'hi abocava, era per «lleialtat» amb ell mateix i amb el seu poble, per «desafiar el desplaçament forçat» (Campillo 2009: 37), per amortir la «separación entre el homo interior y el homo exterior» (Guillén 1998: 63) que fatalment comporta l'expatriació.

Hem vist que Fabra i Coromines coincidien a denunciar el català malgirbat de les publicacions de l'exili. També se'n queixaven tot sovint, en públic o en privat, els escriptors i publicistes, conscients dels perills i de la «inutilitat» de fomentar una llengua corrompuda. En aquests termes s'hi referia Rafael Tasis l'octubre de 1945 des dels Quaderns d'Estudis Politics, Econòmics i Socials de Perpinyà (Tasis 20I2: I45): 
És dolorós, en efecte, haver-ho de constatar, però les publicacions catalanes de l'exili pateixen, en llur majoria, d'una lamentable i imperdonable anarquia lingüística i ortogràfica. Castellanismes i gal-licismes hi pul.lulen, i el sentit de les frases és sovint enterbolit per les giragonses d'una construcció artificial i forastera.

Més genèricament, Xavier Benguerel se’n dolia a l'amic Joan Oliver: «els catalans exiliats parlen una llengua que fa plorar» (Benguerel \& Oliver 1999: 76). El seu cas era molt diferent, per exemple, del d'Aurora Bertrana, que el 2I d'octubre de 1947 s'excusava davant Ferran Canyameres: «Suposo que teniu algú que corregeixi els texts car jo no tinc ni gramàtica, ni diccionari ni vocabulari catalans i ja fa prop de deu anys que no conreo aquesta llengua» (Canyameres 1996: 225). Com advertia el Full Català, referint-se a la mainada, «la llengua materna li fuig dels llavis» ("La caputxeta» I94I: 18).

Els criteris lingüístics de l'editorial més prolífica de l'exili, la de Bartomeu CostaAmic, en bona part van ser fixats per Joan Sales, que hi feia de corrector i hi va fer les primeres armes com a aprenent d'editor (Pasqual 20I2: 4I-46). Sota la seva vigilància, els llibres apareixien en una llengua normativitzada i, en la mesura que els originals ho permetien, funcional i moderna. En paraules del mateix Costa-Amic, «la seva feina no es pot valorar» (Isern I990: 27). En diversos prefacis va justificar l'opció d'actualitzar no tan sols l'ortografia sinó també la morfologia dels textos prefabrians, atès que «en facilitem al públic la lectura sense alterar-ne gens ni mica l'estil» (Verdaguer 1948: 4647). També havia fet tasques editorials per a les «Edicions Catalònia» d'Avel.lí Artís (Férriz Roure 1998: 62-68). Es va responsabilitzar explícitament de les edicions de La nacionalitat catalana (1947), de Prat de la Riba, L’Atlàntida (1945) i Canigó (1948), de Jacint Verdaguer, i les Poesies (1947) de Màrius Torres. Així va canalitzar la seva vocació de «filòleg frustrat» (Coromines \& Sales 2004: 6I), tal com es definia en la primera carta adreçada a Joan Coromines, el 4 de desembre de 1946.

El grup de Lletres, del model de llengua, mai no en va fer bandera. Tot i que també era una de les revistes que sortia amb menys errors gramaticals, no tenia una coherència lingüística comparable a la dels Quaderns de l'Exili, en què tot passava pel sedàs de Sales. A Lletres, l'estil de cada col-laborador hi és més marcat $\mathrm{i}$, en termes generals, la llengua dels originals i de les traduccions, en consonància amb el caràcter més literari, és més «retòrica» $\mathrm{i}$ «lírica», més preservadora. Bartra era autodidacte i de sempre havia maldat per esdevenir Poeta, en majúscules. La llengua li era indispensable, però, segons que reportava el company Pere Vives des del camp d'Adge el 27 d'agost de 1939, "com vas dir tu un cop en aquelles inoblidables passejades pel camp, l'estil 
no és gairebé res» (Vives 1972: 23). Alguns anys més tard, a l'època de Lletres, el I3 de març de 1947 admetia a Antoni Ribera que «el verb l'he hagut d'anar conquerint de mica en mica, penosament» (Bartra 1980: 25).

El debat entre continuïtat i ruptura poc o molt també va concernir el model de llengua — de la llengua expatriada - de les publicacions de l'exili. N'és un exemple la controvèrsia sobre l'ús de formes dialectals que es va generar a Pont Blau, arran de la col-laboració de Joan Fuster i d'altres escriptors valencians i balears, que va separar en dos fronts els que n'eren més partidaris (el director, Vicenç Riera Llorca) dels que no n'eren tant per por de malmetre la unitat de la llengua (Agustí Bartra i Pere Calders), com posen de manifest, entre altres textos, les correspondències publicades fins ara de tots quatre. Poc després Bartra va dirigir la Gaseta de Lletres, el suplement literari de La Nova Revista, de curta vida (mig any del 1956). Obria el primer número amb una "Carta oberta a un escriptor valencià», en què, invocant tothora el llegat de Pompeu Fabra, reiterava la necessitat de cohesionar el «cos literari del nostre idioma comú» per damunt «les tendències dialectals coexistents» (Bartra 1956: 2). Tot seguit es formulava una enquesta sobre el "problema» de "la unitat de la nostra llengua», ressorgit «en la desorientació produïda per les circumstàncies» («Enquesta» 1956: 2), que van respondre en els números següents diversos escriptors de l'interior (de l'exili, solament Baltasar Samper).

Les traduccions fetes «en silenci» —un silenci forçat— per part dels torsimanys vocacionals s'escapaven d'aquestes discussions. El que menys es qüestionava de les que aconseguien sortir a llum era el «model» de llengua de què se servien. Ja feien prou de sortir, en aquelles circumstàncies. En general, si les dues veus, la de l'autor i la del traductor, eren reputades, mereixien l'assentiment immediat, el reconeixement de la falta de crítiques. Xavier Benguerel se'n va beneficiar en donar a conèixer a la revista Germanor, de Santiago de Xile, les versions d'El corb (1944), d'Edgar A. Poe, i d'El cementiri mari (1947), de Paul Valéry.

L'estudi d'aquestes versions primigènies comparades a les posteriors que va publicar aporta dades rellevants sobre la llengua de les traduccions a l'exili (ni que només sigui a tall de tendència). En l'una i en les altres, s'hi observa que «les revisions successives porten cap a una major precisió, però també, de vegades, cap a una major llibertat $i$, sovint, a una major naturalitat i una certa modernització del llenguatge»; és a dir, progressivament s'hi suprimeixen cultismes, retoricismes i imprecisions lèxiques $\mathrm{i}$ s'hi afegeix «una major ductilitat $i$ un registre més planer en les revisions successives al 
llarg dels anys» (Ripoll 2009: 63-64). Així mateix, tant en la primera traducció d'Agustí Bartra de The Waste Land, de T. S. Eliot, dins Una antologia de la lírica nord-americana (I95I), com en la segona, La terra eixorca (1977), hi és perceptible un «desajust entre el registre oral de l'original d'Eliot i el registre literari de la traducción, a causa del «model de llengua del Bartra escriptor, [...] que tendeix al conservadorisme» (Pujol 2009: 295), afaiçonat durant trenta anys de desterrament.

Deixant de banda les opcions rupturistes, la llengua de l'exili, en consonància amb el dramatisme de la situació, propendia a una certa impostació de la veu, a un gust pels mots i les formes que remetien a la catalanitat perduda, sensibles supervivents d'un cant remot, d'abans d'ara.

Montserrat Bacardí Universitat Autònoma de Barcelona montserrat.bacardi@uab.cat

\section{REFERÈNCIES BIBLIOGRÀFIQUES}

Aвrams, S. (2009) "Quelcom neix en tota mort...», Quaderns. Revista de Traducció, I6, pp. 67-73.

Andújar, M. (1949) La literatura catalana en el destierro, Mèxic, [s.n.].

Bacardí, M. (2004) Anna Murià. El vici d'escriure, Barcelona, Pòrtic.

- (2009) «La traducció catalana a l'exili. Una primera aproximació», Quaderns. Revista de Traducció, 16, pp. 9-21.

Bartra, A. (1945) «Comiat a Josep Carner», Lletres, 7, pp. I-2.

- (195I) Una antologia de la lírica nord-americana, Mèxic, Lletres.

- (I956) «Carta oberta a un escriptor valencià», Gaseta de Lletres, I, pp. I-2.

- (1980) Sobre poesia, Barcelona, Laia.

Benguerel, X. (1974) Xavier Benguerel es confessa de les seves relacions amb La Fontaine, Edgar Allan Poe, Paul Valéry, Pablo Neruda, Barcelona, Selecta.

- (1982) Memòria d'un exili: Xile 1940-1952, Barcelona, Edicions 62.

Benguerel, X. \& J. Oliver (I999) Epistolari, ed. de Lluís Busquets i Grabulosa, Barcelona, Edicions 62.

Calders, P. (199i) Josep Carner, Argentona, L'Aixernador. 
Campillo, M. (2009) "Cèsar-August Jordana, El món de Joan Ferrer», Quaderns. Revista de Traducció, 16, pp. 29-42.

Camps i Arbós, J. (2004a) «Les Edicions Proa de Perpinyà (I949-1965)», Els Marges, 72, pp. 45-76.

- (2004b) «Ramon Xuriguera (190I-I966): ideologia, activitat cultural i literatura», Bellaterra, Universitat Autònoma de Barcelona, Departament de Filologia Catalana. Tesi doctoral.

- (2010) L'espantós és el buit, el desert. La correspondència entre Rafael Tasis i Ramon Xuriguera, Barcelona, Publicacions de l'Abadia de Montserrat.

Canyameres, F. (1996) Obra completa, vol. vi, Epistolari (I939-I95I), ed. de Montserrat Canyameres, Barcelona, Columna.

Carner, J. (1944) «De l'art de traduir», Lletres, 3, pp. 4-6.

- (1992) Poesia. Text de l'edició de 1957, revisat i establert per Jaume Coll, Barcelona, Quaderns Crema.

Carner-Ribalta, J. (2009) Memòries. De Balaguer a Nova York passant per Moscou $i$ Prats de Molló, Barcelona, Viena.

Casacuberta, M. (1989) "Quaderns de l'Exili (Mèxic 1943-1947), una revista d'agitació nacional», Els Marges, 40, pp. 87-105.

Casals, G. (1992) «Notes sobre Edicions Catalònia i La Nostra Revista, dues empreses editorials d'Avel-lí Artís», dins IV Jornades d'Estudis Catalano-Americans, Barcelona, Generalitat de Catalunya / Comissió Amèrica i Catalunya, pp. 3I-44.

Castellanos, J. (2000) «L'exili literari català: continuïtat i ruptura», dins M. Aznar Soler (ed.), Las literaturas del exilio republicano de 1939, Sant Cugat del Vallès, GEXEL, pp. 3I-44.

"Catalunya envaïda» (1942), Full Català, ıo, p. ıо.

Coromines, J. (1946) «Xicago, 2I d'octubre de 1946», Quaderns de l'Exili, 24, p. 4.

Coromines, J. \& J. Sales (2004) Epistolari, ed. de Josep Ferrer i Joan Pujadas, Barcelona, Fundació Pere Coromines.

Correspondència amb Agusti Bartra des de l'exili xilè. Cartes de C. A. Jordana, Domènec Guansé i Francesc Trabal (2005), ed. de Jaume Aulet, Terrassa, Ajuntament de Terrassa.

Desclot, M. (2007) «Agustí Bartra, traductor de poesia nord-americana», Rels, io, pp. 28-3I.

Duran, M. (1998) «El doble exili dels poetes catalans a Mèxic. Memòria personal», Catalan Review, XII, 2, pp. 9-I9. 
«Els escriptors catalans i llur aportació obligada a la bibliografia castellana» (I94I), Full Català, 2, p. 2.

«Enquesta» (1956), Gaseta de Lletres, I, p. 2.

Espinós, J. (2000) «Transculturació i exili», dins M. Aznar Soler (ed.), Las literaturas del exilio republicano de 1939, Sant Cugat del Vallès, GEXEL, pp. $25 \mathrm{I}-259$.

Fabra, P. (1947) «Lletres als editors», Quaderns de l'Exili, 26, p. 9.

FAulí, J. (2002) Els Jocs Florals de la Llengua Catalana a l'exili (I94I-1977), Barcelona, Publicacions de l'Abadia de Montserrat.

Ferran de Pol, Ll. (1942) «Stendhal», Full Català, I5, p. 3.

- (1943) «Contra l'obra d'en Josep Carner: Misterio de Quanaxhuata», Quaderns de l'Exili, , , p. 3.

— (1944) «Cultura i "cultura"», Quaderns de l'Exili, 6, p. Iо.

— (1945) «Els Quaderns, revista de grup», Quaderns de l'Exili, I2, pp. I-2.

- (1946) «L'exemple de Provença (A l'entorn de Mireia)», Quaderns de l'Exili, 22, p. 5.

— (1984) «Naixença i mort dels Quaderns de l'Exili», Serra d'Or, 298-299, pp. 23-27.

FÉrriz Roure, T. (1997) "Bartomeu Costa-Amic, un editor català a Mèxic», Revista de Catalunya, I22, pp. II3-I37.

- (1998) La edición catalana en México, Jalisco, El Colegio de Jalisco / Generalitat de Catalunya / Orfeó Català de Mèxic.

Fuster, J. (I995) Papers d'exili. Assaigs, polèmiques i recensions (1950-1967), ed. de Josep Ferrer i Joan Pujadas, Barcelona, Curial.

- (1998) Correspondència, vol. II, Agustí Bartra i altres noms de l'exili americà, ed. de Santi Cortés, València, Edicions 3 i4.

Garcia i Raffi, J. V. (1998) Lluis Ferran de Pol i Mèxic: literatura i periodisme, Barcelona, Publicacions de l'Abadia de Montserrat.

Grifell, Q. (1992) Anna Murià, àlbum de records, Argentona, L'Aixernador.

Guansé, D. (1966) Abans d'ara, Barcelona, Aymà.

Guillén, C. (1998) Múltiples moradas. Ensayos de literatura comparada, Barcelona, Tusquets.

Isern, J. J. (1990) «Bartomeu Costa-Amic, els llibres catalanes d'Amèrica», Serra d'Or, 365, pp. 26-29.

Jocs Florals de la Llengua Catalana. Any LXXXIII de llur restauració (1942), Buenos Aires, Consell de la Comunitat Catalana de la República Argentina.

Just, M. (1939) «Els infants exiliats i llur llengua materna», La Revista dels Catalans d'Amèrica, I, p. 43-44. 
«La bella dorment del bosc. Un conte de Perrault. Traducció de Marià Manent» (1942), Full Català, 8-9, p. 27.

«La caputxeta vermella de Perrault» (I94I), Full Català, I, pp. I8-I9.

Manent, A. (1989) La literatura catalana a l'exili, Barcelona, Curial. "I94I-I946: Un lustre. Els Quaderns de l'Exili i l'exili» (I946), Quaderns de l'Exili, 24, pp. I-3.

Miquel i Vergés, J. M. (1943) «Llibres en català a Mèxic», Quaderns de l'Exili, 2, p. 4. Murgades, J. (1996) «Sinopsi de l'antinoucentisme històric», Llengua \& Literatura,

7, pp. I05-I27.

Murià, A. (1990) Crònica de la vida d'Agustí Bartra, Barcelona, Pòrtic.

Pasqual, M. (2012) Joan Sales, la ploma contra el silenci, Barcelona, A Contra Vent.

«Presentació» (1944), Lletres, I, p. I.

«Propòsit» (1943), Quaderns de l'Exili, I, pp. I-2.

Puimedon Monclús, P. (1996) «Joan Sales. La responsabilitat del supervivent», Barcelona, Universitat de Barcelona, Departament de Filologia Catalana. Tesi doctoral. Pujol, D. (2009) «Agustí Bartra, traductor de The Waste Land: tres observacions», Reduccions, 93-94, pp. 288-30I.

«Retorn al punt de partida» (1943), Quaderns de l'Exili, 2, pp. I-2.

Riera Llorca, V. (1994) Els exiliats catalans a Mèxic, Barcelona, Curial.

Ripoll, J. M. (2009) «El teixit contra la barbàrie: El corb i El cementiri marí per Xavier Benguerel», Quaderns. Revista de Traducció, I6, pp. 55-65.

Ruiz Casanova, J. F. (20II) Dos cuestiones de literatura comparada: Traducción y poesía. Exilio y traducción, Madrid, Cátedra.

SAID, E. W. (2002) Reflexiones sobre el exilio. Ensayos literarios y culturales, Barcelona, Debate.

SAles, J. (1942a) «El temps dels primers Jocs», Full Català, 8-9, pp. 3-4.

— (I942b) «Qüestions de llenguatge. La naturalitat i la correcció», Full Català, II, p. Io.

- (1942c) "L'estel sobre el mur d'Agustí Bartra», Full Català, I4, p. 7.

- (1945) «Els òrsides», Quaderns de l'Exili, I2, pp. 8-IO, I2 i I4.

Soler, M. (1997) «Escriure a fora», Revista de Catalunya, II6, pp. 93-136.

Steiner, G. (2002) Extraterritorial. Ensayos sobre literatura y revolución lingüistica, Madrid, Siruela.

Tasis, R. (20I2) Les raons de l'exili, ed. de Montserrat Bacardí i Francesc Foguet, Valls, Cossetània. 
Montserrat Bacardí

Apunts sobre exili, llengua i traducció

"Teatre català a Buenos Aires. Maria... no siguis tonta!» (I943), Catalunya, I50, p. 25. Verdaguer, J. (I948) Canigó, ed. de Joan Sales, Mèxic, Edicions de la Biblioteca Catalana.

"Veus-aquí una Revista Catalana...» (1939), La Revista dels Catalans d'Amèrica, I, pp. 5-7. VIves, P. (I972) Cartes des dels camps de concentració, Barcelona, Edicions 62. 